\title{
Salbutamol in treatment of heart failure
}

\author{
P D V BOURDILlON, J R DAWSON, R A FOALE, A D TIMMIS, \\ P A POOLE-WILSON, G C SUTTON
}

\begin{abstract}
From the National Heart Hospital, Westmoreland Street; the Cardiothoracic Institute, Beaumont Street, London, and Hillingdon Hospital, Uxbridge, Middlesex
\end{abstract}

SUMMARY The haemodynamic effects of oral and intravenous salbutamol were investigated in 22 patients with chronic heart failure. Intravenous salbutamol $(13 \mu \mathrm{g} / \mathrm{min})$ increased cardiac index by 53 per cent from $1.5 \pm 0.131 / \mathrm{min}$ per $\mathrm{m}^{2}$ to $2 \cdot 3 \pm 0.23 \mathrm{l} / \mathrm{min}$ per $\mathrm{m}^{2}$ and decreased systemic vascular resistance by 28 per cent from $29.4 \pm 3.9$ units to $21.2 \pm 2.5$ units. Heart rate rose by 10 per cent from $101 \pm 3.5$ beats per minute to $111 \pm 3.2$ beats per minute and pulmonary artery end-diastolic pressure fell by 13 per cent from $26.3 \pm 1.8 \mathrm{mmHg}$ to $22.8 \pm 2.1 \mathrm{mmHg}$. Similar results were obtained after oral salbutamol $(8 \mathrm{mg})$. Cardiac index rose by 40 per cent and systemic vascular resistance fell by 30 per cent. There was a small rise in heart rate and a variable and not significant change in pulmonary artery enddiastolic pressure. Experiments on isolated rabbit papillary muscle showed that salbutamol, at the concentration which exists in patients, had no detectable positive inotropic effect. It is probable that the increase in cardiac output in patients is primarily the result of reduced afterload caused by vasodilatation. Salbutamol is a useful drug in the treatment of chronic heart failure.

Vasodilator drugs are widely advocated in the treatment of both acute and chronic heart failure. ${ }^{1-3}$ Salbutamol is a relatively specific beta- 2 adrenergic agonist which relaxes smooth muscle and reduces systemic vascular resistance. ${ }^{4}$ The haemodynamic effects of intravenous salbutamol have been studied in normal persons, ${ }^{5}$ in patients with respiratory disease ${ }^{6}$ in patients after acute myocardial infarction, ${ }^{7}$ in patients with mitral valve disease, ${ }^{8}$ and in patients after cardiac surgery. ${ }^{9-11}$

More recently Sharma and Goodwin ${ }^{12}$ reported the effects of intravenous salbutamol in patients with congestive cardiomyopathy and concluded not only that the drug was beneficial but that its primary action was as a positive inotropic agent. The purpose of the present study was to investigate the haemodynamic effects of both oral and intravenous salbutamol in patients with chronic heart failure. In an attempt to establish whether the effects of salbutamol were attributable to vasodilatation or increased cardiac contractility, experiments were undertaken on isolated right ventricular panillary muscles of rabbits.

\section{Patients}

Salbutamol was administered by either the oral or the intravenous route. Group A consisted of 11 Received for publication 30 July 1979 patients given salbutamol $8 \mathrm{mg}$ orally. There were nine men and two women, aged 31 to 67 years, mean 52 years. Heart failure was the result of coronary artery disease in nine and cardiomyopathy in two. All patients were in sinus rhythm apart from one patient who had a permanent pacemaker implanted for complete heart block.

Group B consisted of 11 patients given intravenous salbutamol in a dose of $13 \mu \mathrm{g} / \mathrm{min}$. There were 10 men and one woman, aged 49 to 78 years, mean 65 years. Heart failure was the result of coronary artery disease in 10 patients and congestive cardiomyopathy in one. All but one patient, who was in atrial fibrillation, were in sinus rhythm.

All patients in both groups had severe heart failure which had not responded satisfactorily to large doses of diuretics. All except four patients were on digoxin. Six of the patients in Group A were able to walk short distances in the ward. The remaining seven patients in Group $A$ and all patients in Group B were confined to bed by the severity of their heart failure.

\section{Methods}

Cardiac output was measured by the thermodilution technique using a Swan-Ganz catheter and a cardiac output computer (Edwards Laboratories, Model 9510-A; Cardiovascular Instruments, 
Model 600). For each measurement the average of three estimations was calculated. The catheter was inserted percutaneously into a subclavian vein and advanced to the pulmonary artery. Measurements were made of the right atrial pressure, pulmonary artery wedge pressure, and pulmonary artery pressure. The wedge pressure correlated closely with the pulmonary artery end-diastolic pressure in all patients. In subsequent recordings the pulmonary artery end-diastolic pressure was used to assess changes in left ventricular filling pressure in most patients in order to avoid frequent manipulation of the catheter. The zero reference point was the sternal angle. Blood pressure was measured with a sphygmomanometer and the heart rate was obtained from the electrocardiogram. Mean blood pressure was calculated as the diastolic pressure plus a third of the pulse pressure. Systemic vascular resistance was calculated as the difference between the mean blood pressure and right atrial mean pressure divided by the cardiac output. Stroke volume index was calculated from the cardiac index and heart rate.

In group A patients, measurements were made at rest and after administration of $8 \mathrm{mg}$ oral salbutamol, at half-hourly intervals for two hours and subsequently at one- or two-hourly intervals for a maximum of seven hours. In six patients two sets of control measurements were made one hour apart. Only small and insignificant changes were observed.

In group B measurements were made under control conditions and $\mathbf{4 0}$ minutes after the start of an infusion of salbutamol at a dose of $13 \mu \mathrm{g} / \mathrm{min}$.

Experiments were undertaken on isolated right ventricular papillary muscles of rabbits $(2$ to $4 \mathrm{~kg}$ ). The experimental preparation has been previously described. ${ }^{13}$ Temperature was $37^{\circ} \mathrm{C}$ and the stimulation rate 60 beats per minute. The muscles were stretched until developed tension was maximal. Developed tension and the first differential of developed tension $(\mathrm{dT} / \mathrm{dt})$ were recorded.

\section{Results .}

GROUP A: ORAL SALBUTAMOL

The changes in cardiac index over the period of the study are shown in Fig. 1. There was a rise in all patients with a peak at an average time of 90 minutes. Cardiac index subsequently fell slowly but did not reach control levels within seven hours.

The changes in cardiac index, heart rate, pulmonary artery end-diastolic pressure, systemic arterial mean pressure, systemic vascular resistance, and stroke volume index at the time of maximum cardiac index are shown in Fig. 2. Cardiac index

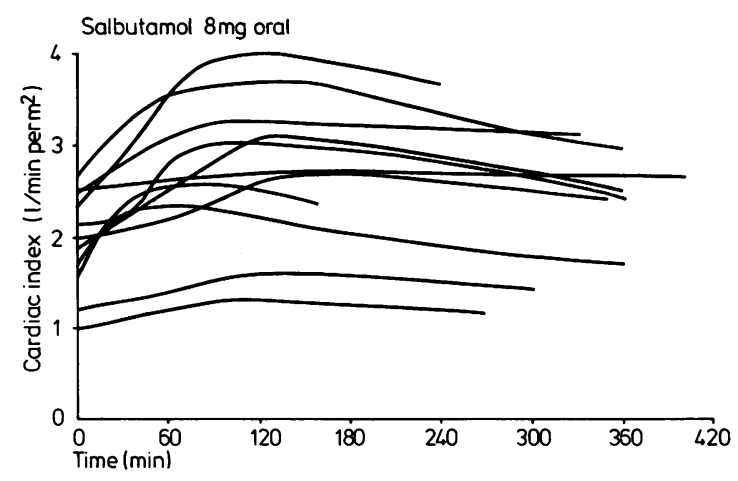

Fig. 1 Group $A$. The changes in cardiac index after oral salbutamol ( $8 \mathrm{mg}$ ).

rose from $2 \cdot 0 \pm 0 \cdot 16 \mathrm{l} / \mathrm{min}$ per $\mathrm{m}^{2}$ to $2 \cdot 8 \pm 0 \cdot 27 \mathrm{l} / \mathrm{min}$ per $\mathrm{m}^{2}$ after salbutamol $(40 \%, \mathrm{p}<0.001)$. Heart rate increased from $83 \pm 3$ to $89 \pm 4$ beats per minute $(7 \%, p<0.05)$. Pulmonary artery end-diastolic pressure fell in six patients, but for the whole group there was no significant change. There was no significant change in mean blood pressure which was $86 \pm 1.8 \mathrm{mmHg}$ before and $82 \pm 2.7 \mathrm{mmHg}$ after salbutamol. Calculated systemic vascular resistance fell from $24.9 \pm 2.8$ units before to $17 \cdot 4 \pm$ 2.2 units after salbutamol $(30 \%, \mathrm{p}<0.001)$. Stroke volume index increased from $25 \cdot 6 \pm 2 \cdot 6$ to $31 \cdot 8 \pm 3 \cdot 0$ $\mathrm{ml} / \mathrm{m}^{2}(28 \%, \mathrm{p}<0.001)$.

One patient in group $\mathrm{A}$ had an episode of angina associated with tachycardia two hours after salbutamol. This patient was treated with sublingual glyceryl trinitrate and the study was discontinued. No other side effects were observed.

GROUP B: INTRAVENOUS SALBUTAMOL

The results are shown in Fig. 3. Cardiac index rose in all patients from $1.5 \pm 0.131 / \mathrm{min}$ per $\mathrm{m}^{2}$ before salbutamol to $2.3 \pm 0.231 / \mathrm{min}$ per $\mathrm{m}^{2}(53 \%, \mathrm{p}<$ $0.001) 40$ minutes after the start of the salbutamol infusion. There was a small but significant increase in heart rate from $101 \pm 3.5$ to $111 \pm 3.2$ beats per minute $(10 \%, \mathrm{p}<0.01)$. Pulmonary artery enddiastolic pressure fell in seven patients and the fall was significant for the group as a whole, from $26.3 \pm 1.8$ to $22 \pm 2 \cdot 1 \mathrm{mmHg}(13 \%, \mathrm{p}<0.01)$. The mean blood pressure rose slightly from $80.5 \pm$ $5.5 \mathrm{mmHg}$ before to $84.6 \pm 5.3 \mathrm{mmHg}$ after salbutamol $(5 \%, p<0.05)$. There was a 28 per cent fall in calculated systemic vascular resistance from $29.4 \pm$ 3.9 to $21.2 \pm 2.5$ units $(p<0.001)$. Stroke volume index increased from $15 \cdot 0 \pm 1 \cdot 2$ to $20 \cdot 6 \pm 2 \cdot 1 \mathrm{ml} / \mathrm{m}^{2}$ $(37 \%, \mathrm{p}<0.001)$. 
In one patient the infusion of salbutamol had to be discontinued because of the appearance of multiple ventricular ectopic beats. There were no other observed side effects in the patients in group B.

Of the patients in group $A$, two died from deterioration of heart failure within four weeks of the initial study, and one died at the time of coronary artery bypass operation six weeks after the study.
Five patients treated with oral salbutamol $(4 \mathrm{mg}$ q.d.s) reported an improvement in their symptoms of breathlessness and three patients were symptomatically unchanged. Of the patients in group B, seven died from deterioration of heart failure within four weeks of the initial study. Two of the remaining patients reported a symptomatic improvement on oral treatment.
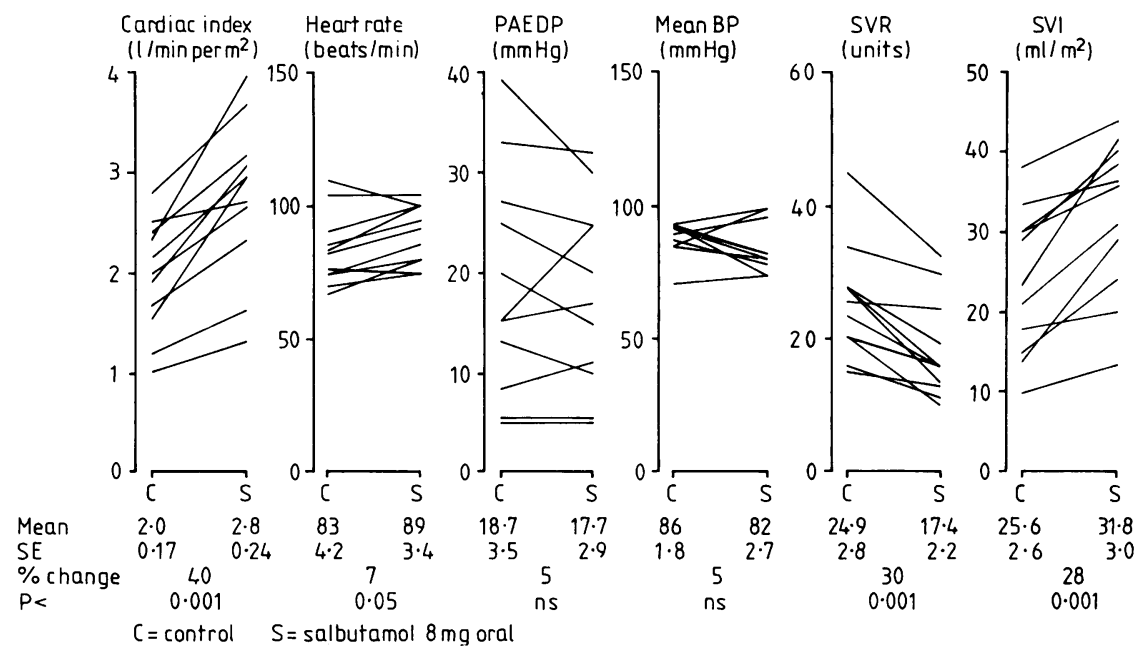

Fig. 2 Group A. Haemodynamic changes after oral salbutamol $(8 \mathrm{mg})$. The changes in cardiac index, heart rate, pulmonary artery end-diastolic pressure (PAEDP), mean blood pressure $(B P)$, systemic vascular resistance ( $S V R)$, and stroke volume index (SVI) are recorded in each case at the time of maximum cardiac index.

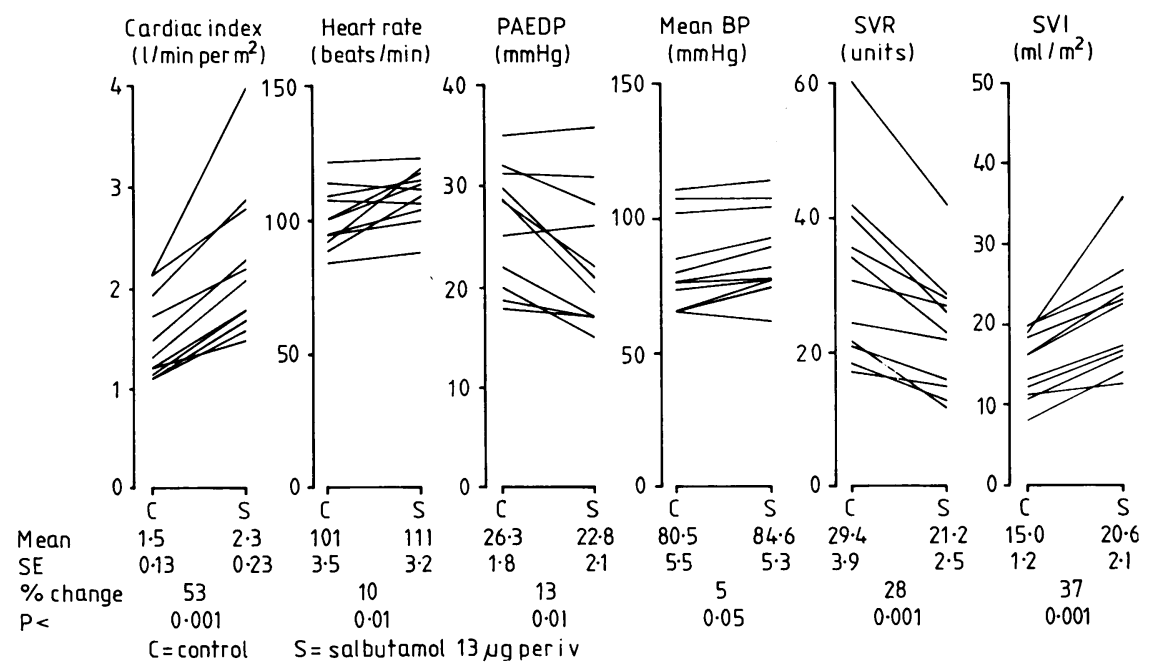

Fig. 3 Group B. Haemodynamic changes during intravenous salbutamol infusion (13 $\mu \mathrm{g} / \mathrm{min})$. The changes in cardiac index, heart rate, pulmonary artery end-diastolic pressure (PAEDP), mean blood pressure (BP), systemic vascular resistance (SVR), and stroke volume index (SVI) are recorded in each case 40 minutes after the salbutamol infusion was started. 


\section{IN VITRO STUDIES}

The changes in developed tension with increasing concentrations of salbutamol in a single experiment are shown in Fig. 4. There is no detectable change with a concentration of $0.01 \mathrm{mg} / 1$. A dose-response curve is shown in Fig. 5 in which a significant increase in developed tension occurs at concentrations of $0.1 \mathrm{mg} / 1$ and above. Similar changes occurred in the positive and negative differential of developed tension.

\section{Discussion}

Oral and intravenous salbutamol have similar haemodynamic effects in patients with chronic heart failure. Salbutamol increases cardiac index and reduces systemic vascular resistance with a small increase in heart rate and a variable or small fall in pulmonary artery end-diastolic pressure. The percentage rise in mean cardiac index $(53 \%)$ and the fall in systemic vascular resistance $(30 \%)$ in patients given intravenous salbutamol are similar to those found by other workers in patients after cardiac surgery, ${ }^{11}$ with congestive cardiomyopathy, ${ }^{12}$ and with mitral valve disease. ${ }^{8} \mathrm{We}$ did not find the same rise in heart rate as did Poole-Wilson et al. ${ }^{11}$ and Gibson and Coltart, ${ }^{8}$ but the smaller change in our patients is similar to that recorded by Sharma

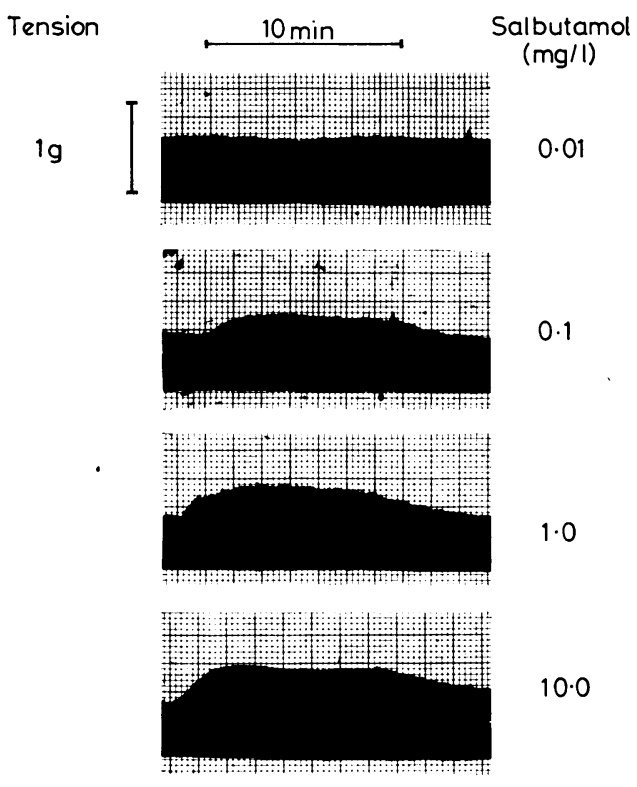

Fig. 4 Changes in developed tension in isolated right ventricular papillary muscle of a rabbit with increasing concentrations of salbutamol. and Goodwin ${ }^{12}$ in patients with cardiomyopathy and some degree of cardiac failure. It appears that in patients with heart failure the effect of salbutamol on heart rate is small.

Several differences were apparant under control conditions between the groups of patients given oral and intravenous salbutamol. The group given intravenous salbutamol had more severe heart failure, were more limited by symptoms, had a lower cardiac index $(p<0.05)$ and stroke volume index $(p<0.001)$, and had a higher heart rate $(p<0.01)$. Both groups of patients responded to salbutamol in a similar manner, in that cardiac index increased and systemic vascular resistance fell (Fig. 2 and 3) but in the group given intravenous salbutamol there was a rise in blood pressure and a fall in pulmonary end-diastolic pressure, which were not seen in the group given oral salbutamol. These differences might be attributable to the different routes of administration of the drug but are more probably a reflection of the more severe heart failure in the group given intravenous salbutamol. The pulmonary artery end-diastolic pressure in the group given oral salbutamol fell in the five patients with the highest initial pressures; the failure of the group as a whole to show a significant fall is partly the result of the inclusion of patients whose control pulmonary artery enddiastolic pressures were low as a result of treatment with powerful diuretics. In these patients the pulmonary artery end-diastolic pressure presumably increases on the mildest exertion since breathlessness was the predominant symptom. Even in the group given intravenous salbutamol the fall in

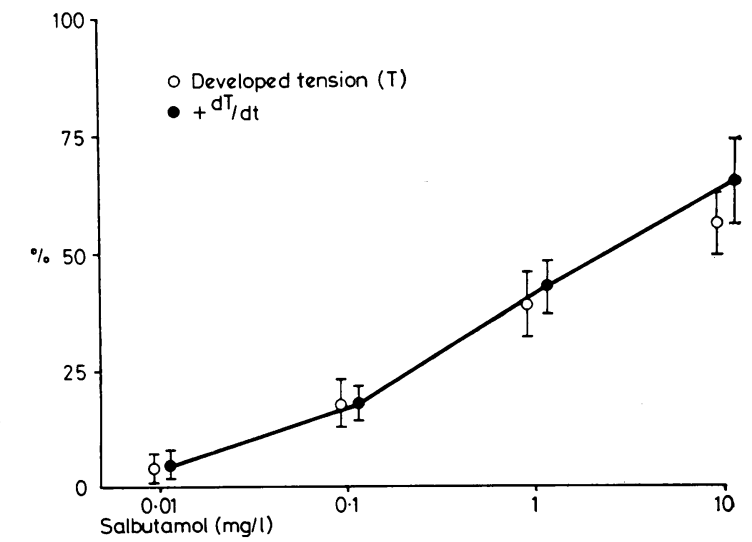

Fig. 5 Dose-response curve for changes in developed tension $(T)$ and $d T / d t$ in isolated rabbit right ventricular papillary muscle $(n=5)$ with increasing concentrations of salbutamol. 
pulmonary artery end-diastolic pressure, though statistically significant, was small $(3.5 \mathrm{mmHg})$.

The haemodyanamic effects of salbutamol could be the consequence of vasodilatation or the result of a positive inotropic effect. The former is more probable since salbutamol is known to be a beta-2 agonist ${ }^{4}$ with beta-1 activity only at high concentrations. The problem cannot be resolved in vivo because of the difficulties in distinguishing between an increase in cardiac output resulting from a fall in systemic vascular resistance and an increase in cardiac output resulting from increased contractility with reflex vasodilatation. The in vitro experiments reported here show no significant positive inotropic effect at a concentration of $0.01 \mathrm{mg} / \mathrm{l}$. Though plasma salbutamol concentration was not measured in this study, previous work (D A Richards, 1978, personal communication) has shown a linear relation between infusion rate maintained for one hour and mean plasma salbutamol concentration. Infusion rates of 50,40 , and $30 \mu \mathrm{g} / \mathrm{min}$ produced plasma concentrations of $0.036,0.027$, and $0.022 \mathrm{mg} / \mathrm{l}$, respectively. The estimated plasma concentration with an infusion rate of $13 \mu \mathrm{g} / \mathrm{min}$ would be $0.009 \mathrm{mg} / \mathrm{l}$, a concentration which produced no positive inotropic effect in isolated rabbit papillary muscle. Though considerable caution is required in applying animal results obtained in vitro to studies in man, equally our findings do not lend support to the suggestion ${ }^{12}$ that the effects of salbutamol in the doses used in this study are primarily a result of a positive inotropic action. The increase in cardiac output is probably consequent upon the reduction of systemic vascular resistance.

Our results show clearly that oral and intravenous salbutamol increase cardiac output. The fall in pulmonary artery end-diastolic pressure was small and a drug with a greater venodilator effect may be indicated in patients with heart failure and a high pulmonary artery end-diastolic pressure at rest. Though we have used salbutamol orally (4 mg q.d.s.) for periods greater than two months in 10 patients with sẹvere chronic heart failure, we have no objective evidence of improvement. Nevertheless, our clinical impression is that in these patients symptomatic benefit is appreciable and side effects rare. A beneficial effect is by no means invariable and we have found no simple method of selecting those who will improve. Salbutamol can also be useful in the treatment of patients confined to bed in hospital with heart failure and oedema unresponsive to large doses of diuretics and digoxin. Intravenous salbutamol was given to such patients for periods of three to 20 days. This treatment enabled patients who previously were languishing in hospital beds to return home.

We wish to thank Glaxo Group Research Ltd. and Allen \& Hanbury Ltd. for their assistance.

\section{References}

${ }^{1}$ Cohn JN. Blood pressure and cardiac performance. Am f Med 1973; 55: 351-61.

${ }^{2}$ Chatterjee K, Parmley WW. Vasodilator treatment for acute and chronic heart failure. Br Heart $\mathcal{F} 1977$; 39: 706-20.

${ }^{3}$ Awan NA, Miller RR, DeMaria AN, Maxwell KS, Neumann A, Mason DT. Efficacy of ambulatory systemic vasodilator therapy with oral prazosin in chronic refractory heart failure: concomitant relief of pulmonary congestion and evaluation of pump output demonstrated by improvements in symptomatology, exercise tolerance, haemodynamics and echocardiography. Circulation 1977; 56: 346-54.

${ }^{4}$ Cullum VA, Farmer JB, Jack D, Levy GP. Salbutamol: a new selective $\beta$-adrenoceptive receptor stimulant. Br f Pharmacol 1969; 35: 141-51.

${ }^{5}$ Leitch AG, Clancy LJ, Costello JF, Flenley DC. Effect of intravenous salbutamol on ventilatory response to carbon dioxide and hypoxia and on heart rate and plasma potassium in normal men. $B r$ Med $\mathcal{F} 1976$; 1 : 365-7.

'Warrell DA, Robertson DG, Newton Howes J, et al. Comparison of cardiorespiratory effects of isoprenaline and salbutamol in patients with bronchial asthma. Br Med f 1970; 1: 65-70.

${ }^{7}$ Lal S, Savidge RS, Davies DM, Ali MM, Soni V. Intravenous salbutamol and cardiogenic shock. Lancet 1972; 1 : 853-4.

${ }^{8}$ Gibson DG, Coltart DJ. Haemodynamic effects of intravenous salbutamol in patients with mitral valve disease: comparison with isoprenaline and atropine. Postgrad Med f 1970; 47: Suppl. (March), 40-4.

${ }^{9}$ Yacoub MH, Boyland E. Cardiovascular effects of intravenous salbutamol after open heart operations. Lancet 1973; 1: 1260-1.

${ }^{10}$ Wyse SD, Gibson DG, Branthwaite MA. Haemodynamic effects of salbutamol in patients needing circulator support after open-heart surgery. $\mathrm{Br} \mathrm{Med} \mathcal{F}$ 1974; 3: 502-3.

${ }^{11}$ Poole-Wilson PA, Lewis G, Angerpointer T, Malcolm AD, Williams BT. Haemodynamic effects of salbutamol and nitroprusside after cardiac surgery. Br Heart f 1977; 39: 721-5.

${ }^{12}$ Sharma B, Goodwin JF. Beneficial effect of salbutamol on cardiac function in severe congestive cardiomyopathy: effect on systolic and diastolic function of the left ventricle. Circulation 1978; 58: 449-60.

${ }^{13}$ Poole-Wilson PA, Cobbe SM, Fry CH. Acute effects of diuretics on potassium exchange, mechanical function and the action potential in rabbit myocardium. Clin Sci Mol Med 1978; 55: 555-9.

Requests for reprints to Dr P. A Poole-Wilson, Cardiothoracic Institute, 2 Beaumont Street, London W1N 2DX. 